\title{
Left Lung Agenesis with Bicuspid Aortic Valve
}

\author{
Taran $\mathbf{S J}^{1}$, Kumar $\mathbf{R}^{2}$, Lodha $\mathbf{M}^{3}$
}

\begin{abstract}
Agenesis of the lung is an extremely rare congenital anomaly representing failure of development of the primitive lung bud. Here we are presenting a case of left lung agenesis with bicuspid aortic valve in a 17 year old girl who came with the complaints of backache only. The diagnosis was made on the basis of CECT and 2D Echocardiography.
\end{abstract}

Key words: Agenesis, Lung, Bicuspid aortic valve, Unilateral, Paediatrics

\section{Introduction}

$\mathrm{M}$ ajor congenital anomalies of lung such as hypoplasia and agenesis are very rare entity and seldom being reported ${ }^{1}$. They have varied clinical presentation ranging from totally asymptomatic to severe respiratory insufficiency. Lung agenesis and or hypoplasia often misdiagnosed or underdiagnosed on radiograph because of its similarity with other more common medical conditions like collapse, pleural effusion, mucous plug, foreign body and pnuemonectomy etc.

\section{The Case}

A 17 year old female presented to our clinic with complaints of backache since 5-6 days after some weightlifting. On examination she had mild drooping of left shoulder and scoliosis with convexity towards right in high thoracic spine. On respiratory system examination chest movement on left side were decreased with decreased vocal fremitus and dull note on percussion. Auscultation showed breath sounds were absent in most of the left lung fields but there was no respiratory distress. Trachea and heart were shifted to left side. X-ray Chest [Fig $1 \mathrm{~A}$ ], spine AP and lateral revealed opaque left hemithorax with crowding of ribs in superior area with mild scoliosis. On taking history retrospectively she had history of fatigue but there was no history of dyspnea, weight loss, loss of appetite, or any other respiratory symptom. Since clinical examination and $x$-ray findings were not matching. Patient was advised computed tomography scan chest which revealed crowding of ribs on left side, mediastinal shift to left, left pleural cavity absent, left lung, left main bronchus and left pulmonary artery not seen, left diaphragm
Dr. Shachi Jain Taran, MBBS, MD, Assistant Professor, Department of Paediatrics, Sri Aurobindo Medical College and PG Institute, Indore, India, ${ }^{2}$ Dr. Ravindra Kumar, PhD, Central Research Laboratory, Sri Aurobindo Medical College and PG Institute, Indore, India, ${ }^{3} \mathrm{Dr}$. Manish Lodha, MD, Department of Radiodiagnosis, Synergy Hospital, Indore, India.

\section{Address for correspondence:}

Dr. Shachi Jain Taran

E-mail: shachitaran@yahoo.co.in

\section{How to cite}

Taran SJ, Kumar R, Lodha M. Left Lung Agenesis with Bicuspid Aortic Valve. J Nepal Paediatr Soc 2014;34(2):147-149.

doi: http://dx.doi.org/10.3126/jnps.v34i2.8792

This work is licensed under a Creative Commons Attribution 3.0 License.

cc) (i)

high up [Fig 1B to 1E]. Trachea was on right side with compensatory emphysema and hypertrophy of right lung, right pulmonary artery and its branches were normal. Bony cage was normal except for crowding of ribs on left side. All these finding were compatible with left pulmonary agenesis. Pulmonary function test result was suggestive of restrictive lung disease. On 2D echocardiography, bicuspid aortic valve and only two pulmonary veins draining into left atrium were seen. Main pulmonary artery bifurcation could not be visualized. No other congenital anomaly was found. 

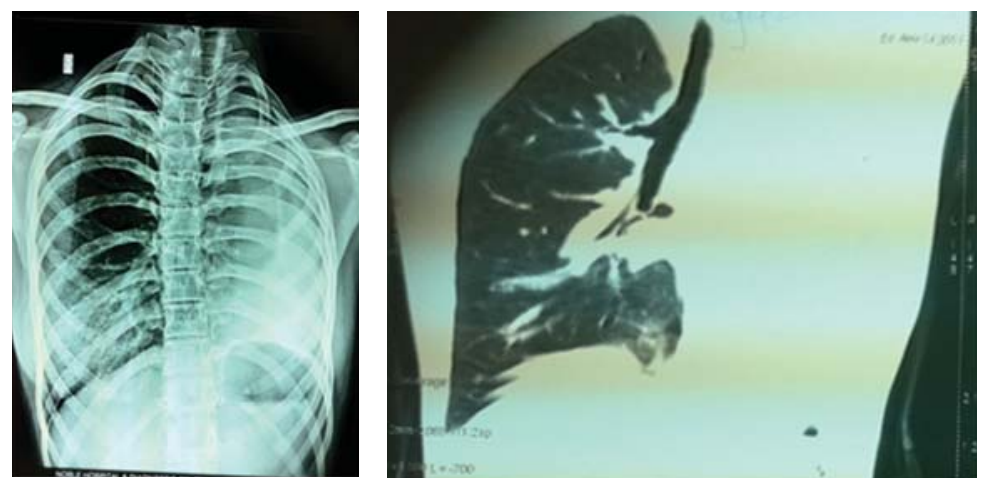

Fig. 1A: Chest $X$ ray of Fig. 1B: Contrast enhanced computed patient showing left tomography of chest showing no hemithorax opacity bifurcation of trachea which is continuing as right main bronchus. Left main bronchus not visualized.

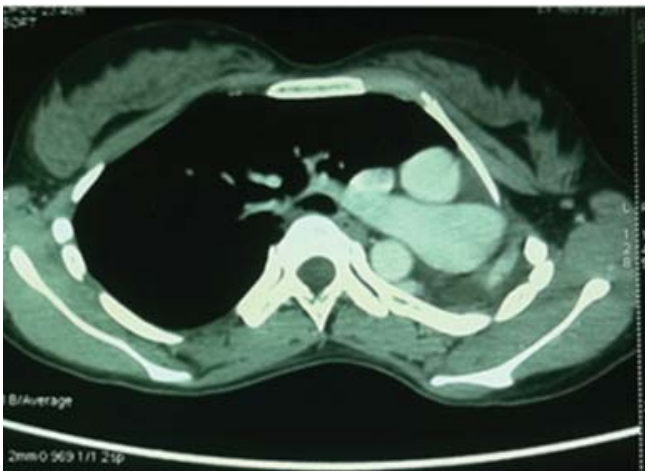

Fig. 1C: Contrast enhanced computed tomography of chest showing main pulmonary trunk and right pulmonary artery, left pulmonary artery not seen.

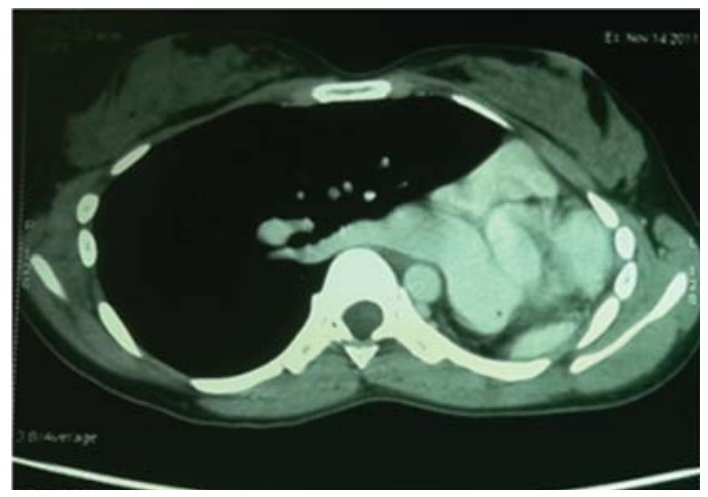

Fig. 1D: Contrast enhanced computed tomography of chest showing right sided pulmonary veins draining into left atrium, no left sided veins seen.

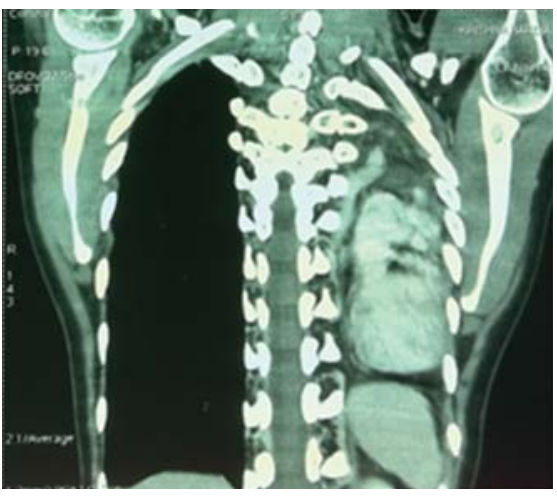

Fig. 1E: Contrast enhanced computed tomography of chest showing right lung hypertrophy with absent left lung and mediastinal shift to the left.

\section{Discussion}

Agenesis of lung is extremely rare congenital anomaly first described by De Pozze, who discovered it accidently in 1673 at the autopsy of an adult female ${ }^{2}$. It is thought to have an incidence of approximately 1 in 100000 children $^{3}$. In India first case was reported by Muhamed in 1923 which was also an autopsy finding ${ }^{4}$. With the advancement of diagnostic modalities detection of such cases during life has risen considerably.

Lung agenesis is the result of failure of the development of respiratory system from foregut during embryogenesis. Type and severity of defect depend on the time of insult during organogenesis. Arrest at the stage of primitive lung bud produces bilateral lung agenesis. The insult at later stage may lead to unilateral agenesis. Lobar agenesis occurs when development arrest happens in one side of older embryo. Pulmonary hypoplasia may occur during the last trimester of pregnancy with failure of final alveolar differentiation ${ }^{5}$.

The primary causes of pulmonary hypoplasia includes some role of TTF-1, hepatocyte nuclear factor HNF310, epidermal growth factor and its receptor (EGFR) and secondary causes includes small fetal thoracic volume, prolonged oligohydramnios, decreased fetal breathing, congenital heart diseases and trisomies $18,13,21^{6}$.

First classification of the condition was given by Schneider in $1912^{7}$. Later Boyden ${ }^{8}$ has provided more practical classification based on degree of developmental arrest. The categories are as follows-

(a) Group I-Complete absence of lung and bronchus and no vascular supply to the affected side.

(b) Group II -Rudimentary bronchus with complete absence of pulmonary parenchyma. 
(c) Group III-Presence of variable amounts of bronchial tree, pulmonary parenchyma and supporting vasculature

Left pulmonary agenesis is often an isolated finding but recently, Di George syndrome and velo-cardiofacial syndrome have been reported in association with left pulmonary agenesis ${ }^{9,10}$. Cardiovascular anomalies are usually acyanotic but rarely anomalous pulmonary venous return, tetralogy of fallot, and single ventricles are also reported. Nearly $50 \%$ cases of right pulmonary agenesis have associated congenital defects which usually involve cardiovascular, skeletal, gastrointestinal and genitourinary system ${ }^{11}$. Congenital absence of breast is rare re. $^{12}$.

The onset of symptoms in pulmonary agenesis is remarkably variable. In many cases, presence of this anomaly usually comes to light during infancy because of recurrent chest infections, cardiopulmonary insufficiency or due to associated congenital anomalies. However, patients with one lung have been reported to survive well into adulthood without much complaints and oldest patient was 72 years old ${ }^{13}$. Prognosis in such cases depends upon two things - firstly severity of associated congenital anomalies, secondly involvement of normal lung in other disease process.

Our patient is among those rare cases of left lung agenesis with bicuspid aortic valve who is asymptomatic till now as per respiratory symptomatology is concerned. This was an incidental diagnosis in a case of backache which was probably due to scoliosis. This patient belonged to group 1 of Boyden classification as there was no left main bronchus and left pulmonary artery. To best of our knowledge no other case of left lung agenesis with bicuspid aortic valve has been reported till now.

\section{Conclusion}

Whenever coming across a case of one hemithorax opacity and clinical finding do not match radiograph, we must include rare conditions like unilateral lung agenesis into our differential diagnosis.

\section{References}

1. Bhattacharjee S1, Deb J, Dattachaudhuri A, Tapadar SR, Dhua A, Mukherjee T, Ghosh P Unilateral lung hypoplasia: a rare cause of unilateral opaque hemithorax in chest X-ray in a young boy. Indian J Med Sci 2012;66(7-8):192-6.

2. De Pozze S. cited by Brescia M.A., Amermon E.E., Sharma K.K. Agenesis of the Left Lung. Arch Paediatric 1960;77: 485-90.

3. Yetim TD, Bayaroğullari H, Yalçin HP, Arica V, Arica SG. Congenital Agenesis of the Left Lung: A Rare Case. J Clin Imaging Sci 2011;1:47

4. Muhamed, KSN. Absence of left lung. Ind Med Gaz 1923;58:262-64.

5. Krummel TM. Congenital malformations in the lower respiratory tract. In: Chernick V, Boat T F, Kendig E L. Kendig's Disorders of The Respiratory Tract in Children. 6th Ed. Philadelphia: WB Saunders Company; 1998; 307-8.

6. Warburton D, Olver BE. Coordination of genetic, epigenetic, and environmental factors in lung development, injury, and repair. Chest 1997;111(6):119S-122S.

7. Schneider P. in Schwalbe E. Die Morphologie der Misshildungen des Menschen und der Tiere, 3, pt. 2, 772. G. Fischer, Jena. 1912

8. Boyden E. Developmental anomalies of lung. Am J Surg 1955;89:79-88

9. Fitoz S, Ucar T, Erden A, Gunlemez A. Degeorge syndrome associated with left lung aplasia. $\mathrm{Br} J$ Radiol 1992;65:221- 224.

10. Conway K, Gibson RL, Perkins J, Cunningham ML. Pulmonary agenesis: expansion of the VCFS phenotype. Am J Med Genet 2002;113: 89-92

11. Maltz DL, Nadas AS. Agenesis of the lung: presentation on of eight new cases and review of literature. Pediatrics 1968;42:175-88

12. Singh TG, Vijendra G, Kumar CC. Unilateral pulmonary agenesis: A case report. Novel Sci Int J Med Sci 2012;1(6):174-7

13. Kisku KH, Panigrahi MK, Sudhakar R, Nagarajan A, Ravikumar R, Daniel JR. Agenesis of lung - a report of two cases. Lung India 2008;25(1):28-30. 